\title{
Imaging diagnosis of metastatic breast cancer
}

\author{
Filippo Pesapane ${ }^{1 *}$, Kate Downey ${ }^{2}$, Anna Rotili ${ }^{1}$, Enrico Cassano ${ }^{1}$ and Dow-Mu Koh ${ }^{3,4}$
}

\begin{abstract}
Numerous imaging modalities may be used for the staging of women with advanced breast cancer. Although bone scintigraphy and multiplanar-CT are the most frequently used tests, others including PET, MRI and hybrid scans are also utilised, with no specific recommendations of which test should be preferentially used. We review the evidence behind the imaging modalities that characterise metastases in breast cancer and to update the evidence on comparative imaging accuracy.
\end{abstract}

Keywords: Bone metastases, Breast cancer, Cancer staging, Oncology, Positron-emission tomography, Radiology

\section{Key points}

1. Combined local- and whole-body staging is crucial for breast cancer treatment.

2. Bone scintigraphy is easy to read, widely available and cost effective.

3. Whole-body-MRI/hybrid imaging is increasingly performed for distant staging.

4. PET-CT may detect metastases with higher sensitivity than conventional imaging.

5. WBMRI also plays a role in the detection of visceral and skeletal involvement.

\section{Introduction}

Due to the rising incidence of breast cancer, it is estimated that breast cancer-related deaths will increase by 43\% globally from 2015 to 2030 [1]. At presentation, 4$10 \%$ of breast cancers are metastatic [2] and accurate staging of breast cancer is crucial for guiding treatment and optimising patient outcome. Imaging provides information regarding the presence, extent and distribution of metastatic disease. The aim of this review is to critically evaluate the current imaging techniques for the detection of metastatic disease in breast cancer,

\footnotetext{
* Correspondence: filippo.pesapane@ieo.it; filippopesapane@gmail.com ${ }^{1}$ Breast Imaging Division, IEO - European Institute of Oncology IRCCS, Via Giuseppe Ripamonti, 435, 20141 Milano, MI, Italy

Full list of author information is available at the end of the article
}

highlighting the new and emerging methods to optimally stage patients with advanced disease.

\section{Literature search strategy and selection criteria \\ Using a software based on statistical text mining and machine learning methods [3], we identified 33 relevant articles in PubMed on staging of advanced breast cancer, metastatic breast cancer, bone disease and distant metas- tases between 2009 and 2019. We identified papers in English language, both original studies and review arti- cles. Additionally, we searched the references listed for additional relevant papers, using a total of 40 scientific papers.}

\section{Staging of breast cancer for metastatic disease}

The most common staging system for breast cancer is the American Joint Committee on Cancer (AJCC) TNM [4], which is based on tumour size and the degree of locoregional invasion by the primary tumour $(\mathrm{T})$, the extent of regional lymph node involvement $(\mathrm{N})$ and presence (or absence) of distant metastases (M) [5] (Table 1). M1 indicates the presence of any metastases to distant organs, implying a stage IV disease (regardless of the $\mathrm{T}$ or $\mathrm{N}$ status). Breast cancer may be stage IV at first diagnosis, or it can be recurrent from previous breast cancer. Stage IV disease showed a 5-year survival rate of approximately $22 \%$, although this rate varies according to other factors, such as the hormone receptor 
Table 1 Breast cancer staging

\begin{tabular}{|c|c|c|c|c|}
\hline Stage & $T$ & $\mathrm{~N}$ & M & Description \\
\hline 0 & Tis & No & MO & $\begin{array}{l}\text { Tumour that has not grown beyond its site of origin } \\
\text { and invaded the neighbouring tissue. It includes the } \\
\text { DCIS and LCIS. }\end{array}$ \\
\hline $\mid A$ & $\mathrm{~T} 1$ (tumour $\leq 20 \mathrm{~mm}$ ) & No & MO & $\begin{array}{l}\text { Tumour which is not 'in situ' but it is } \leq 20 \mathrm{~mm} \text { in } \\
\text { greater dimension }\end{array}$ \\
\hline $\mathrm{IB}$ & T0 or T1 & N1mi (micrometastases) & Mo & $\begin{array}{l}\text { Tumour } \leq 20 \mathrm{~mm} \text { in greater dimension with nodal } \\
\text { micrometastasis (greater than } 0.2 \mathrm{~mm} \text { and/or more } \\
\text { than } 200 \text { cells, but none greater than } 2 \mathrm{~mm} \text { ) }\end{array}$ \\
\hline \multirow[t]{2}{*}{$\| \mathrm{A}$} & T0 or T1 & $\begin{array}{l}\text { N1 (metastases in 1-3 ipsilateral } \\
\text { ALN(s) }\end{array}$ & Mo & \multirow{2}{*}{$\begin{array}{l}\text { Tumour } \leq 20 \mathrm{~mm} \text { in greater dimension with } \\
\text { involvement of axillary lymph nodes or tumour from } \\
20 \text { to } 50 \mathrm{~mm} \text { without involvement of any ALNs }\end{array}$} \\
\hline & $\mathrm{T} 2(20 \mathrm{~mm}<$ tumour $\leq 50 \mathrm{~mm})$ & No & Mo & \\
\hline \multirow[t]{2}{*}{$\| \mathrm{B}$} & $\mathrm{T} 2$ & N1 & Mo & \multirow{2}{*}{$\begin{array}{l}\text { Tumour from } 20 \text { to } 50 \mathrm{~mm} \text { with involvement of ALNs } \\
\text { or tumour }>50 \mathrm{~mm} \text { without involvement of any ALNs }\end{array}$} \\
\hline & $\mathrm{T} 3$ (tumour > $50 \mathrm{~mm}$ & No & Mo & \\
\hline \multirow[t]{2}{*}{ IIIA } & $\mathrm{T} 0, \mathrm{~T} 1$ or $\mathrm{T} 2$ & $\begin{array}{l}\text { N2 (metastases in 4-9 ipsilateral } \\
\text { ALNs) }\end{array}$ & MO & \multirow{2}{*}{$\begin{array}{l}\text { Tumour }>50 \mathrm{~mm} \text { with spread to ALNs, or tumour } \\
\text { of any size with metastases in ALNs which are } \\
\text { knitted to each other or with the surrounding tissue }\end{array}$} \\
\hline & T3 & $\mathrm{N} 1$ or N2 & Mo & \\
\hline$\| I B$ & $\begin{array}{l}\text { T4 (tumour of any size with } \\
\text { direct extension to the chest } \\
\text { wall and/or to the skin }\end{array}$ & No, N1, N2 & Mo & $\begin{array}{l}\text { Tumour of any size with metastases into the skin, } \\
\text { chest wall or internal LNs of the mammary gland }\end{array}$ \\
\hline IIIC & Any $T$ & $\begin{array}{l}\text { N3 (metastases in } \geq 10 \text { ALNs, or in } \\
\text { infra-clavicular LNs or ipsilateral } \\
\text { internal mammary LNs) }\end{array}$ & Mo & $\begin{array}{l}\text { Tumour of any size with a more widespread } \\
\text { metastases and involvement of more LNs }\end{array}$ \\
\hline IV & Any $T$ & Any N & $\begin{array}{l}\text { M1 (distant } \\
\text { organs' } \\
\text { metastases) }\end{array}$ & $\begin{array}{l}\text { Any tumour spreads to parts of the body that re } \\
\text { located far removed from the chest (bones, lungs, } \\
\text { liver or distant LNs) }\end{array}$ \\
\hline
\end{tabular}

ALN axillary lymph node, DCIS ductal carcinoma in situ, LCIS lobular carcinoma in situ, LN lymph node

- T2, T3 and T4 tumours with nodal micrometastases (N1mi) are staged using the N1 category

- M0 means that there are no clinical or radiographic evidence of distant metastases. It includes also Mo(i+) that indicates the presence of tumour cells or deposits $<0.2 \mathrm{~mm}$ detected microscopically or by molecular techniques in circulating blood, bone marrow or other nonregional nodal tissue in a patient without clinical and radiographic evidence of distant metastases

- Stage $3 a$ is broadly known as a local spread of breast cancer

- T4 does not include the invasion of dermis alone

- If a patient presents with M1 disease prior to neoadjuvant systemic therapy, the stage is considered stage IV and remains stage IV regardless of response to neoadjuvant therapy

- Stage designation may be changed if postsurgical imaging studies reveal the presence of distant metastases, provided the studies are performed within 4 months of diagnosis in the absence of disease progression, and provided the patient has not received neoadjuvant therapy

status [6]. The median survival for patients with breast cancer and bone metastases is 65 months in the oestrogen/progesterone-receptor-positive (ER/PR-positive) groups, and 40 months in both the human epidermal growth factor receptor 2 (HER-2) positive and 'triple-negative' group [7].

Multi-modality imaging is widely used clinically for disease staging. However, all cancers are potentially systemic diseases and whole-body imaging techniques, such as whole-body hybrid imaging (PET-CT and/or PETMRI) or whole-body magnetic resonance imaging (WBMRI) are increasingly performed to reflect this.

\section{The approach to the patient with suspected advanced breast cancer}

There are now effective lines of treatment for patients with metastatic disease, which can improve symptoms, prevent complications and prolong life [8-13]. Furthermore, oligometastatic disease (typically $<5$ metastases), may be suitable for aggressive local therapy in combination with systemic treatment. Hence, the combined assessment of local disease and whole-body staging, together with better understanding of the tumour molecular characteristics, is key to individualised treatment $[14,15]$.

The detection of breast cancer metastases in breast cancer varies according to disease stage. In early breast cancer, routine staging evaluations are directed at locoregional disease [16] as in stages $\mathrm{T} 1$ and $\mathrm{T} 2$ primary breast cancers, the incidence of distant metastases is < 2\% [17] compared with $15-20 \%$ in stage T3 or T4 [18]. Accordingly, the American Society of Clinical Oncology (ASCO), the European Society for Medical Oncology (ESMO) and the Royal College of Radiologists (UK), in their clinical practice guidelines for breast cancer (updated in 2018, 2019 and 2014, respectively), do not recommend routine imaging for the M-staging of asymptomatic patients with early 
stage disease. Staging imaging studies are usually performed for patients at high risk of disease spread, such as stage T3/4 cancers $(>5 \mathrm{~cm})$, in patients with 4 or more involved axillary lymph nodes or in the setting of recurrent disease $[16,19]$.

The incidence of bone metastases in ER/PR positive cancer, which may establish upwards of 10-20 years after initial diagnosis [20], is significantly higher than the incidence of other site of metastases, namely is reportedly $18.7 \%$ (in luminal A subtype) to $30.4 \%$ (in luminal B subtype) [21]. Furthermore, the molecular subtype of the breast cancer influences the likelihood of metastatic spread: women with ER/PR-negative tumours have a higher risk of metastatic relapse in the first 5 years [20, 21] compared with ER/PR-positive tumours.

Current international guidelines lack consensus as to whom and how to image for metastatic disease [22]. Traditionally, high-risk patients were screened for occult metastases using bone scintigraphy (BS), chest radiography and abdominal ultrasound or bone scintigraphy and CT of the chest abdomen and pelvis. However, the use of next generation imaging, such as hybrid imaging (PET-CT and/or PET-MRI) and WBMRI, has increased over the years [17]. Indeed, traditional conventional imaging frequently detects bone disease and visceral metastases in late stages, which are associated with poorer outcomes. Moreover, these methods often fail to demonstrate the heterogeneity of the tumour biology, leading to delay in the detection of treatment resistance and the opportunity for therapeutic modifications [15].

The ESMO's guidelines recommend performing chest, and abdominal imaging (US, CT or MRI scan) and a bone scan can be considered for patients with clinically positive axillary nodes, large tumours (T3/4) or tumours with aggressive biology. If such methods are inconclusive, dual imaging methods combining functional and anatomical information such as ${ }^{18}$ F-FDG PET-CT are suggested [16].

The Royal College of Radiologists (UK) recommends staging with $\mathrm{CT}$ of the chest abdomen and pelvis for patients with large (T4) tumours or with heavy lymph node burden (N2 disease) with or without bone scan and a PET-CT for suspected inflammatory breast cancer.

The latest North American National Comprehensive Cancer Network (NCCN) guidelines [23] recommend BS, abdominal CT/MRI (including the pelvis if symptomatic), chest $\mathrm{CT} /{ }^{18} \mathrm{~F}-\mathrm{NaF}$ PET-CT, in symptomatic patients or in stage I-IIB breast cancer and abnormal liver function test, elevated serum alkaline phosphatase, localised bone pain. The ${ }^{18} \mathrm{~F}$-FDG PET-CT is often recommended when the findings of conventional imaging are suspicious or uncertain. BS or ${ }^{18} \mathrm{~F}-\mathrm{NaF}$ PET-CT may be bypassed when ${ }^{18} \mathrm{~F}$-FDG PET-CT has already detected skeletal metastasis. Other requests for imaging may result from multi-disciplinary team discussions, e.g. in patients with triple negative invasive carcinoma, or in ipsilateral recurrence within the breast [24].

Regarding bone metastases, every above-mentioned imaging modality evaluates different aspects of the tumour: BS estimates osseous remodelling and osteoblastic activity, CT reveals bone destruction and/or presence of sclerosis, diffusion-weighted MRI assesses tissue cellularity and PET-CT using FDG tracer evaluates increased glycolytic metabolism [25]. Conventional imaging is limited when detecting small bone metastases: BS may have an unsatisfactory performance for lytic lesions, metastases with low bone turnover and low vascularity. CT usually demonstrates lytic lesions associated with bone destruction, but disease confined to the bone marrow may be missed [25].

In the next section, we review the diagnostic utility of conventional imaging (BS, CT and MRI) and next generation imaging (PET-CT, PET-MRI and WBMRI) for assessing the presence, extent and biological characteristics of bone and visceral metastases in patients with breast cancer.

\section{Conventional imaging \\ Radionuclide bone scan \\ Planar bone scintigraphy (BS)}

Planar BS is clinically easy to read, widely available and cost effective [26], and has been recommended as the primary technique to detect bone metastases in asymptomatic high-risk breast cancer women [17].

Abnormal accumulation of ${ }^{99 \mathrm{~m}} \mathrm{Tc}$-labelled diphosphonates is connected to increased local blood flow and osteoblastic activity which occur consequently to metastatic growth within bone marrow [17, 27-30]. The sensitivities of planar BS reportedly range between 62 and $100 \%[17,27-31]$. However, ${ }^{99 \mathrm{~m}}$ Tc-labelled diphosphonates are nonspecific markers of osteoblastic activity which are also observed in benign fractures, Paget's disease, degenerative joint diseases, trauma and inflammation [31-33]. This accounts for the lower specificity of planar BS $(0.75,0.71-0.79)$ than SPECT $(0.85$, 0.80-0.90) (Table 2) [29, 34-36].

\section{SPECT bone scan}

An overall improvement was observed when BS was augmented using single-photon emission computerised tomography (SPECT) in the lower thoracic and lumbar spine, or across the entire axial skeleton (whole-body SPECT) (Fig. 1) [37, 39-41]. On a per-patient basis in breast cancer, SPECT showed a higher specificity of $94 \%$ compared with $74 \%$ using BS [42]. Although some preclinical SPECT scanners can provide a sub-millimetre spatial resolution, clinical gamma cameras yield a tomographic resolution of about $10 \mathrm{~mm}$ [38]. Hence, like 
Table 2 Studies comparing diagnostic performance of BS and SPECT

\begin{tabular}{lllllll}
\hline Ref & First author & Year & Patients/lesions & Study design & Sensitivity of BS (vs. SPECT) & Specificity of BS (vs. SPECT) \\
\hline$[29]$ & Shen & 2014 & N/R & Met-analyses & $59 \%(v s .90 \%)$ & 745 (vs. 85\%) \\
{$[34]$} & Giovanella & 2011 & $194 / 245$ & Prospective & $75 \%($ vs. 95\%) & $74 \%$ (vs. 82\%) \\
{$[35]$} & Nozaki & 2008 & $39 / 116$ & N/R & N/R & 69\% (vs. 90\%) \\
{$[36]$} & Palmedo & 2014 & $211 / 353$ & Prospective & $93 \%$ (vs. 94\%) & $77 \%$ (vs. 95\%) \\
{$[37]$} & Even-Sapir & 2006 & $44 / 156$ & Prospective & $70 \%$ (vs. 92\%) & 57\% (vs. 82) \\
{$[38]$} & Khalil & 2011 & N/R & Systemic review & N/R & $74 \%$ (vs. 94\%) \\
\hline
\end{tabular}

planar BS, the spatial resolution of SPECT is limited [41]. Accordingly, the diagnostic effectiveness of SPECT has been questioned and patients with uncertain findings often demand other radiological exams to characterise indeterminate findings [43-45].

Combining SPECT with CT partially improves the performance for metastatic bone disease, by lowering the number of equivocal lesions detected on planar BS $[26,36,46]$. However, such combined technique may not be widely available because of higher equipment costs, and image quality may be reduced by patient movement and CT artefacts [26].

\section{CT}

In clinical practice, plain radiographs are often used as an adjunct to BS, to evaluate symptomatic bone pain. Bone scan findings are often corroborated using CT [17], which shows a good specificity although a poor sensitivity $(95 \%$ and $73 \%$ respectively, according to
Heindel et al.) [47]. Metastases appear on CT as areas of lucency or sclerosis, and rarely as well-defined radiodensity within the bone marrow [21].

Concerning visceral metastases, liver localisations are quite common in patients with breast cancer (up to 60$70 \%$ of women have liver metastases at autopsy) [48]. Sensitivity and specificity for detecting liver metastases were reported $73-75 \%$ and $94-96 \%$, respectively, while for US, MRI and FDG-PET were 61-65\% and 96-98\%, $80-82 \%$ and $96-98 \%$ and $94-96 \%$ and $98-99 \%$, respectively [49-51].

Generally, HER2-expressing breast cancers tend to metastasise to the liver more frequently than ER/PRpositive breast cancers $[52,53]$. Portal venous phase of CT shows liver metastases as irregular hypodense lesions with peripheral contrast enhancement [54]. Nevertheless, liver metastases may appear isodense with the hepatic parenchyma (Fig. 2) and their extent may be underestimated or, when diffuse, entirely missed [21].
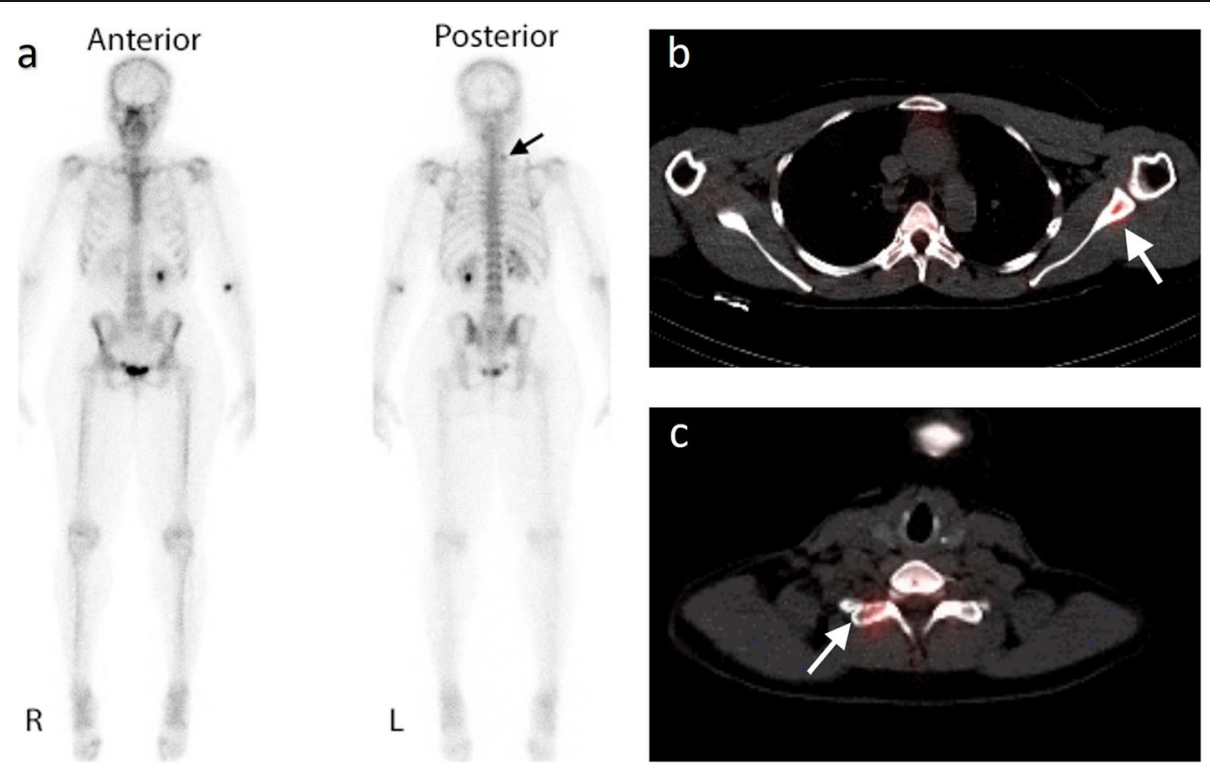

Fig. 1 Planar bone scan versus SPECT. Images from a planar bone scan (a) and views from a single-photon emission computerised tomography (SPECT) through the thoracic (b) and cervical (c) spine in a 56-year-old woman with breast cancer. Subtle abnormal tracer accumulation is present at the root of the left neck on the planar bone scan (black arrow) with normal accumulation within the urinary tract and at the injection site (a). SPECT-CT demonstrates corresponding uptake in right transverse process of C7 (c white arrow) but additional uptake in the left scapula (b white arrow) not visible on the planar images alone 


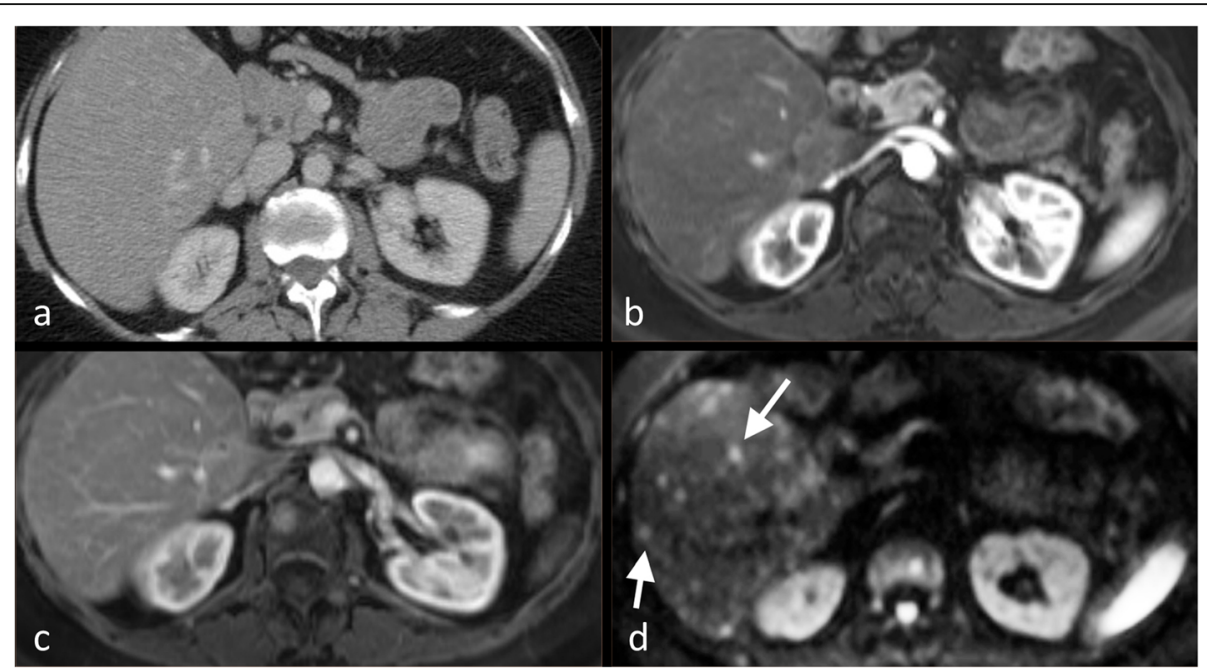

Fig. 2 Isodense liver metastases not visualised on CT identified using MRI. Images from a portal venous phase CT (a), arterial (b) and portal venous (c) phase T1-W post-contrast MRI and b-750 diffusion-weighted MRI (d) through the liver in a 46-year-old woman with breast cancer and deranged liver function. The liver appears normal on both CT and T1-W post-contrast MRI but multiple high signal foci are present throughout the liver (white arrows) on the diffusion-weighted sequence in keeping with diffuse liver metastases

No differences were observed in the CT appearances of liver metastases according to the molecular hormonal receptor status [55].

Similarly, higher percentages of brain metastases are found in hormone ER/PR-negative breast cancers when compared with the hormone-positive subtypes [52]. Moreover, triple negative breast cancer subtype shows higher risk of developing brain metastases [56]. Performing CT of the brain is commonly induced by clinical symptoms such as mental status change, headache or vomiting/nausea. In this setting, MRI is preferred, where and when available, due to its enhanced sensitivity [21]. From the radiologist's perspective, although innovative treatment may prolong overall survival, a higher rate of cerebral metastases is reported in such patients, as novel therapeutics may not be effective across the blood-brain barrier [57].

Lung metastases from breast cancer may be showed on CT in a number of radiological patterns: singular or multiple pulmonary nodules, endobronchial localisation, air-space consolidation and lymphangitic carcinomatosis, which may simulate other primaries such as pulmonary adenocarcinoma or lymphoma [21] (Fig. 3). Pleural localisation frequently reveals as a unilateral (and ipsilateral to the breast cancer) pleural effusion, with no specific features compared with benign effusions [21].

\section{Conventional MRI}

In metastatic breast cancer, malignant cells displace and replace normal bone marrow fat cells causing a reduction in fat content, whereas successful management is associated with return of healthy bone marrow fat [58].
MRI can differentiate healthy from pathological bone marrow acting as an effective and non-invasive test to recognise bone metastases $[17,28,59,60]$. MRI sequences including T1WI, diffusion-weighted imaging (DWI) and Dixon quantitative chemical shift imaging (which estimates water and fat fraction) can evaluate the anatomical and functional features of bone marrow [58, 61]. Therefore, a trained radiologist can discriminate bone metastases (which manifest with nodular focal metastatic lesions or marrow infiltration/replacement) from benign marrow alterations (such as marrow hyperplasia induced by chemotherapy) [28].

Studies evaluated MRI as the primary screening technique for diagnosing skeletal deposits to associate the advantages of high sensitivity and specificity with improved spatial resolution, demonstrating the diagnostic superiority of MRI over BS for identifying bone metastases $[62,63]$. Particularly, an updated meta-analysis showed a pooled sensitivity of $97 \%$ for MRI versus $79 \%$ for BS and a pooled specificity of $95 \%$ versus $82 \%$, respectively [29].

Additionally, MRI is commonly used to clarify equivocal findings from BS [28] and to detect complications associated with bone metastases (such as compression of spinal cord or nerves), which can alter management decisions [64]. Altehoefer et al. [65] showed how MRI guided the need for local therapy in sites that were negative on BS; Kim et al. [66] highlighted the value of MRI for the evaluation of single 'hot spots' on BS [67]. However, interpretation of bone MRI needs an understanding of the evolution of normal bone marrow with age: indeed in younger patients, highly cellular hematopoietic 


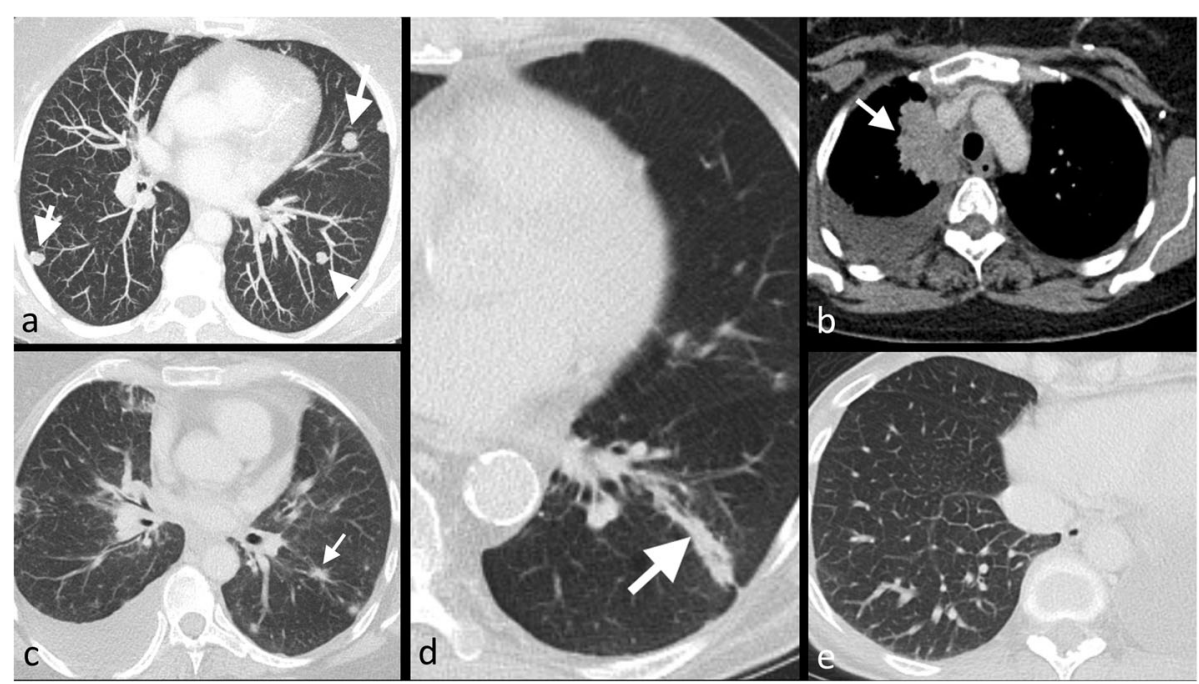

Fig. 3 Morphological appearances of lung metastases. Maximum intensity projection (MIP) CT thorax (a), and portal venous phase CT thorax using mediastinal windows (b) and portal venous phase CT on lung windows (c, $\mathbf{d}$ and $\mathbf{e}$ ) in a 62-year-old woman with differing morphological appearances of metastatic breast cancer to the lungs. The MIP CT demonstrates multiple rounded lung metastases (a), a mass lesion simulating lung cancer (b), irregular spiculated metastases (c), endo- and peribronchial infiltration (d) and lymphangitis carcinomatosis (e)

marrow may make it more difficult to diagnose small metastases [68].

With an $80-82 \%$ and $96-98 \%$ reported ranges of sensitivity and specificity, respectively [49-51], MRI is an appropriate modality to detect hepatic metastases [69]. Breast cancer metastases in liver are typically hypo- to isointense on T1WI, iso- to hyperintense on T2WI and, since breast metastases are frequently hypovascular, they usually show perilesional enhancement [70] in the arterial phase of contrast enhancement. However, hypervascular metastases may also occur, which can be associated with disease progression (Fig. 4). In addition, DWI can aid the detection of small liver metastases easily overlooked on other sequences [69]. Pretreatment enhancement features of liver metastases at MRI, such as the degree of hypervascularity of the tumour rim, may also predict disease progression [71].

For the detection of brain metastases, contrastenhanced MRI has higher sensitivity than CT [72], due to its higher soft tissue resolution and its better detection of parenchymal and leptomeningeal involvement [21]. Lesions are usually supratentorial, and they can be solitary or multiple, arising at the grey-white matter junction and at watershed zones of major arterial territories [73] (Fig. 5). Moreover, MRI showed higher sensitivity and specificity than PET-CT for brain metastases [74] as the high background activity present in the cortex and basal ganglia (due to intrinsic high glucose consumption of these structures) can substantially degrade signal-to-noise ratio of FDG PET [72], therefore adversely affect the ability of PET to detect especially small metastatic lesions.

Nevertheless, according to the updated ASCO's guidelines, clinicians should not perform routine MRI to screen all the breast cancer patients for brain metastases but only in patients with HER2-positive advanced breast cancer because their high incidence of brain metastases [75].

Lungs are frequently involved by breast cancer metastases: with advanced MR techniques, lung metastases may be visualised as foci of high signal on DWI [10].

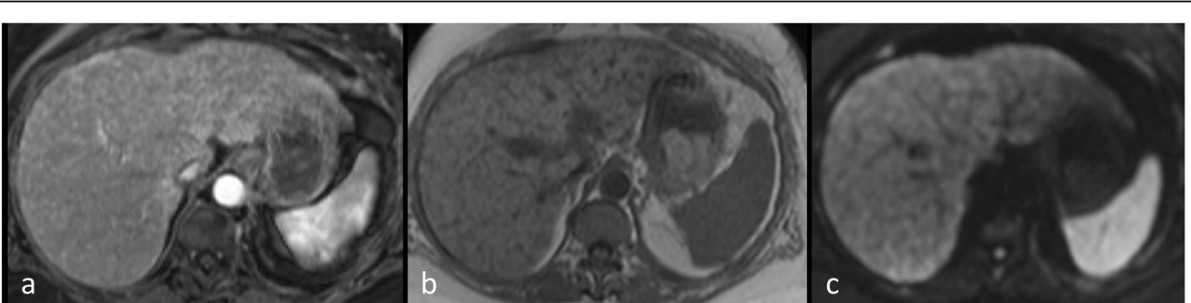

Fig. 4 Hypervascular liver metastases on MRI. Liver MRI in a 52-year-old woman with breast cancer demonstrates multiple slightly T1 hyperintense lesions in the liver on the T1-W image (a) which show increased enhancement in portovenous phase (b) and impeded diffusion on b750 DWI (c) 


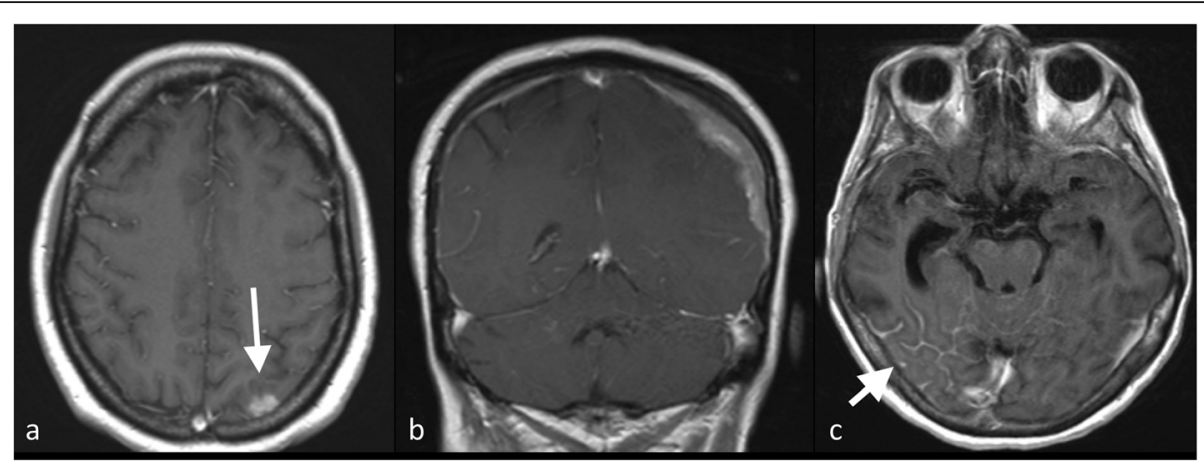

Fig. 5 Cerebral manifestations of breast cancer. Post-contrast T1-W MRI in a 58-year-old woman with breast cancer demonstrates intracerebral metastases (a), dural metastasis (b) and leptomeningeal disease (c)

\section{Advanced imaging}

Among the various imaging modalities currently available for distant metastases detection, hybrid techniques which fuse morphological and functional data are the most sensitive and specific, and PET-CT and PET-MRI will probably continue to evolve and become increasingly important in this field. Different imaging modalities are often used in combination to optimally detect bone metastases. Although conventional imaging has frequently been used for cancer staging, these methods have been found to be less sensitive and less specific in providing accurate data in a clinically relevant time frame. Owing to positive recent developments in advanced imaging, the current trend is toward whole-body imaging in a single session. The choice of modality is usually based on the clinical situation and the type of primary tumour. Further research is warranted to further address the impact of these costly and labourintensive imaging methods on treatment strategies and on the course of illness. Below, we discuss recent evidences on advanced imaging methods including PETCT, PET-MRI and WBMRI. These modalities generally show improvements in diagnostic accuracy for detection of metastases over conventional imaging methods, with the ability to quantify biological processes related to the bone microenvironment as well as tumour cellularity. Comparative studies between conventional and advanced imaging techniques have also been carried out in subjects selected for further investigation after bone scan, and the contribution of hybrid imaging and WBMRI to evaluate bone/visceral lesions or suspicious symptoms have been reported [67].

\section{Hybrid imaging}

The use of hybrid imaging (PET-CT and PET-MRI) has increased thanks to the increased access to commercial radiopharmaceutical production facilities and to the widespread availability of scanners [76]. The net clearance of $18 \mathrm{~F}$-sodium fluoride $\left({ }^{18} \mathrm{~F}-\mathrm{NaF}\right)$ in breast cancer bone metastases is $3-10$ times greater than that in healthy bone, conferring the capacity to detect both osteolytic and osteosclerotic metastases [77]. The mechanism of uptake of $18 \mathrm{~F}-\mathrm{NaF}$ tracer into bones is like that of ${ }^{99 \mathrm{~m}} \mathrm{Tc}$ diphosphonates, being related to local blood flow and osteoblastic activity, with rapid initial uptake into bone mineral as fluorapatite. ${ }^{18} \mathrm{~F}-\mathrm{NaF}$ PET-CT has better diagnostic performance than ${ }^{18} \mathrm{~F}-\mathrm{NaF}$ PET alone without the CT component [78].

In oncological staging, 18F-fludeoxyglucose $\left({ }^{18} \mathrm{~F}-\mathrm{FDG}\right)$ is the most widely used radiotracer [76]: its uptake in skeletal metastases is pretended to be largely within tumour cells acting as a breast cancer-specific tracer rather than reflecting alterations in the bone microenvironment [79] (Fig. 6).

The Royal College of Radiologists (UK) recommends the consideration of PET-CT for staging breast cancer patients in those with multifocal disease, suspected recurrence when breast MRI is not possible and in symptomatic patients with an equivocal MRI. In addition, breast cancer patients under the age of 40 may benefit from PET-CT in early disease as this may result in upstaging of systemic sequelae [19].

The underlying histologic subtype of breast cancer may also influence the choice of PET imaging. Untreated invasive lobular carcinoma may have poorer ${ }^{18} \mathrm{~F}-\mathrm{FDG}$ uptake of the osteoblastic metastases compared with invasive ductal or mixed subtypes [80]. Similarly, previous treatment history is significant, as ${ }^{18} \mathrm{~F}$-FDG-negative skeletal metastases may show increased sclerotic following successful systemic therapy, which renders tumour cells nonviable even though ongoing reparative osteoblastic activity, as detected by BS or ${ }^{18} \mathrm{~F}-\mathrm{NaF}$ PET may endure [81].

\section{PET-CT}

There is increasing evidence that PET-CT detects distant metastases with higher sensitivity than conventional 


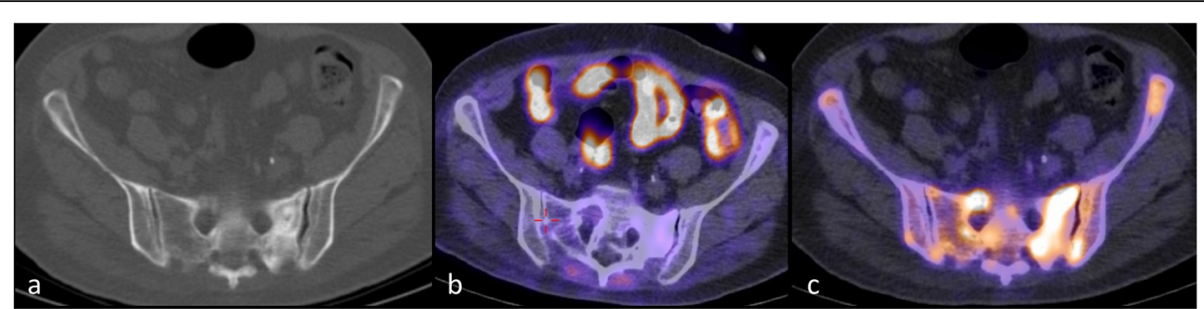

Fig. 6 Comparison of NaF and FDG PET-CT In the same 65-year-old woman with metastatic breast cancer a CT (a) shows increased sclerosis in the left sacrum, increased tracer uptake of NaF PET in left sacrum and also in both ilium (b) but disease activity less well seen on FDG PET (c)

imaging [82], although in cases of lobular cancers and low-grade tumours, PET-CT may be less sensitive [83].

In 2012, Brennan and Houssami [84] published a systematic review of studies evaluating the accuracy of imaging for detecting asymptomatic metastases in 14, 824 patients with breast cancer. They showed a $7.0 \%$ (1.2-48.8\%) prevalence of distance metastases, and the following diagnostic sensitivity/specificity: combined conventional imaging 78.0\%/91.4\%; BS 98.0\%/93.5\%; CT chest/abdomen 100\%/93.1\%; FDG-PET 100.0\%/96.5\%; PET-CT 100\%/98.1\%, respectively. Accordingly, the performance of both conventional and advanced imaging was very high, but these findings could have been biased by patient selection in each category: in comparative studies, PET-CT had significantly higher sensitivity (98.7\%, 78-100\%) than conventional imaging (70\%, 37.5-85.9\%).

Minamimoto et al. [85] prospectively evaluated combined ${ }^{18} \mathrm{~F}-\mathrm{NaF}$ and ${ }^{18} \mathrm{~F}$-FDG PET-CT in 15 women with breast cancer and 15 men with prostate cancer and compared the results with those of BS and WBMRI (including DWI). For bone metastases, PET-CT demonstrated better sensitivity and accuracy than WBMRI (96.2\% vs. $81.4 \%, 89.8 \%$ vs. $74.7 \%$,) and BS (96.2\% vs. $64.6 \%, 89.8 \%$ vs. $65.9 \%$,), while, for visceral metastases, ${ }^{18} \mathrm{~F}-\mathrm{NaF} /{ }^{18} \mathrm{~F}-$ FDG PET-CT and WBMRI had no statistically significant difference in sensitivity, PPV or accuracy.

The higher lung tissue contrast of the CT and its lower susceptibility to motion artefacts facilitate the detection of lung lesions [68] and, some authors support PET-CT as currently the best advanced imaging method for detecting lung metastases, with a sensitivity of $89 \%$ for PET-CT compared to $82 \%$ for WBMRI and 74\% for PET-MRI [86, 87].

Additionally, PET-CT is useful for the detection of metastatic mediastinal and supraclavicular lymph nodes and a recent meta-analysis [88] reported a sensitivity, specificity, positive predictive value, negative predictive value and accuracy for detecting nodal spread of $84 \%, 92 \%, 74 \%$, $82 \%$ and $81 \%$, respectively. According to Schmidt et al. [89], PET-CT appears to have an increased specificity for neoplastic axillary and mediastinal lymph nodes compared to WBMRI, namely $90 \%$ versus $86 \%$.

\section{PET-MRI}

The combination of PET with MRI may benefit from the high soft tissue contrast of MRI with the additional use of multi-parametric MRI. Moreover, PET-MRI systems overcome pitfalls of PET-CT, such as uptake in bowel loops and ureters, which may lead to false positive findings [90].

However, while claustrophobia is not an issue with PET-CT, many patients do experience it with PET-MRI due to a combination of the relatively narrower and longer bore and the use of whole-body anterior surface coils and a head coil required for the MRI portion of the exam [91]. Moreover, PET-CT protocols are usually completed within $30 \mathrm{~min}$, which are faster than PETMRI that is designed to take advantage of multisequences MRI, resulting in studies that may exceed an hour in length with discomfort of many cancer patients who are unable to remain supine and still for long time due to pain [91]. Although some authors proposed faster and abbreviated PET-MRI protocols [92-95] that allow PET-MRI to rival PET-CT for speed, such protocols often do not take full advantage of PET-MRI and may fail to justify the additional expense of PET-MRI.

Tumours that are assessed by both PET-CT and MRI could be transferred to PET-MRI [76] as it allows combined local and whole-body staging in breast cancer, providing an improved lesion detection in the brain, breast, liver, kidneys and bones. Indeed, MRI can provide an anatomic correlate for an FDG-avid lesions and it can detect bone metastases with low FDG uptake (which are not detectable on PET-CT) $[82,96]$. According to Melsaether et al. [87], PET-MRI outperformed PET-CT in the detection of metastatic breast cancer and it showed, at the same time, a dose reduction averaging of $50 \%$. Even though PET-CT detects more pulmonary lesions than PET-MRI, the clinical significance of lung lesions missed on PET-MRI is unclear [97]. On the other hand, Riola-Parada et al. [98] in their systematic review of 57 articles evaluating the PET-MRI versus PET-CT in the metastases detection showed a similar diagnostic performance between the two modalities except for small lung metastases, for which PET-CT was superior. 
Although PET-CT has the advantage in terms of overall acquisition time due to the rapid nature of CT scanning, PET-MRI may acquire higher quality PET images due to longer time available for acquisition and the ability to use MRI respiratory gating information to improve PET data [91]. Usually, MRI exams are obtained in the anatomic target/region of interest and hence extra time spent at this bed position permits a longer PET acquisition providing increased detector counts and improved image quality. Moreover, because MRI sequences are typically obtained during breath-holds or using respiratory gating, PET data can be reconstructed with selected data at motion free time points, allowing for decrease in motion artefact [91].

In conclusion, PET-CT is currently an established technology already in widespread and accepted use worldwide, while PET-MRI has higher cost and major complexity of operating and interpreting the findings. However, PET-MRI can decrease radiation dose and improve motion correction [91].

\section{Whole-body MRI}

The introduction of DWI and apparent diffusion coefficient (ADC) improved the accuracy of MRI for metastases detection [99-101]. Using whole-body DWI with STIR fat suppression in free breathing optimises the image signal-to-noise ratio and image quality $[102,103]$. In addition to axially acquired DWI, T1WI, STIR and/or T2-weighted fat-suppressed images are usually also obtained [104]. Regarding the choice of $b$ value, at least two $b$ values are suggested: the higher $b$ value chosen usually ranges between 600 and $1000 \mathrm{~s} / \mathrm{mm}^{2}$, while the lower $\mathrm{b}$ value ranges between 0 and $100 \mathrm{~s} / \mathrm{mm}^{2}$ [102]. The protocol currently used for WBMRI is feasible, reproducible and can be performed in a relatively short time [10].

In metastatic breast cancer, DWI appears equally sensitive but less specific than 19F-FDG PET-CT in the bone metastases evaluation, indicating that it should not be read in isolation but in correlation with morphologic imaging [105]. In 2010, a prospective study [106] enrolling 36 patients with prostate or breast cancer showed a better performance of WBMRI in detecting malignant skeletal lesions (sensitivity $97 \%$ vs. 91\%) compared to BS (sensitivity $97 \%$ and $48 \%$, respectively). The recent SKELETA trial [124] compared the diagnostic accuracy of BS, SPECT, SPECT-CT, ${ }^{19} \mathrm{~F}-\mathrm{NaF}$ PET-CT and WBMRI for the detection of bone metastases in 26 breast and 27 prostate cancer patients, reporting the following sensitivity values, $62 \%, 74 \%, 85 \%, 93 \%$ and $91 \%$, respectively, resulting in an analogous diagnostic accuracy to $19 \mathrm{~F}-$ NaF PET-CT and outperformed SPECT-CT and BS.

Yang et al. [128] performed a meta-analysis in several tumour types, including breast cancer, and showed that
WBMRI and PET-CT resulted superior to CT and BS in terms of both sensitivity and specificity to detect bone metastases. Particularly, the sensitivity rates for PET-CT, CT, MRI and BS were $89.7 \%, 72.9 \%, 90.6 \%$ and $86.0 \%$, respectively, and the specificity rates were $96.8 \%, 94.8 \%$, $95.4 \%$ and $81.4 \%$, respectively. Results of singular studies are showed in Table 3.

The reasons for false positive results on WBDWI include bone marrow oedema caused by benign conditions, which can be overcome by correlating the high $b$ value DWI with related ADC maps and conventional MRI sequences based on T1W.

A number of studies translationally analysed the differences between normal bone marrow and metastatic lesions, correlating ADC with cellularity and other histological characteristics in bone metastases [58, 108, 109]: this is essential for qualification of MRI as a prognostic biomarker in metastatic breast cancer [17, 20, 21, 52].

In addition, WBMRI can play a role in the assessment of visceral metastases [62, 110], where WBMRI has a better sensitivity than PET-CT to evaluate small hepatic and brain metastases (Fig. 7) [69, 89]. There is also an evolving role for the use of WBDWI to assess the treatment response of metastatic bone disease to systemic and targeted therapies (Fig. 8).

\section{Future perspectives}

Nowadays, the processes of breast cancer metastasis have been well characterised at the molecular level and numerous biomarkers of tumour aggressiveness have been discovered and are ready to be tested in clinics. As we have discussed, molecular imaging offers the opportunity to depict specific cell markers relevant to tumour aggressiveness. For instance, Harmon et al. [111] recently compared in a prospective way the ${ }^{18} \mathrm{~F}-\mathrm{NaF}$ PET-CT with ${ }^{18} \mathrm{~F}-\mathrm{N}-[\mathrm{N}-[(\mathrm{S})-1,3$-dicarboxypropyl] carbamoyl]-4-F-fluorobenzyl-L-cysteine (DCFBC) PET-CT in patients with prostate cancer. Interestingly, this study appears to show that such tracer uptake depends on the disease course and treatment status, which may indicate a functional difference in bone metastases. The study showed that ${ }^{18} \mathrm{~F}$-DCFBC PET-CT detected significantly less bone lesions, especially in patients who were found to be castrate sensitive. On the other hand, in more advanced disease, there was good concordance between the two radiotracers. ${ }^{18} \mathrm{~F}$-DCFBC, though, demonstrates a high blood-pool uptake and such second-generation tracer may elucidate more functional information on the pathophysiology of bone metastases.

Although target-specific molecular imaging probes for tumour invasiveness have been developed for PET (i.e. proteases associated with tumour invasion, such as specific matrix metalloproteinases or cathepsins, can be targeted 'in vivo' with PET), they have not yet been widely 
Table 3 Studies comparing diagnostic performance of WBMRI and PET-CT

\begin{tabular}{|c|c|c|c|c|c|c|c|c|}
\hline$\overline{R e f}$ & $\begin{array}{l}\text { First } \\
\text { author }\end{array}$ & Year & Population & $\begin{array}{l}\text { Use } \\
\text { of } \\
\text { DWI }\end{array}$ & $\begin{array}{l}\text { Sensitivity } \\
\text { of WBMRI } \\
\text { (vS. PET-CT) }\end{array}$ & $\begin{array}{l}\text { Specificity } \\
\text { of WBMRI } \\
\text { (vs. PET-CT) }\end{array}$ & $\begin{array}{l}\text { Accuracy of } \\
\text { WBMRI } \\
\text { (vs. PET-CT) }\end{array}$ & Comments \\
\hline [9] & Jacobs & 2018 & 22 patients with stage IV & Yes & $\begin{array}{l}96 \% \text { (vs. } \\
80 \%)\end{array}$ & $N / R$ & $N / R$ & $\begin{array}{l}\text { ADC values were significantly increased in bone } \\
\text { lesions while they were decreased in soft tissue } \\
\text { metastases. }\end{array}$ \\
\hline [107] & Schmidt & 2007 & $\begin{array}{l}30 \text { patients with different } \\
\text { stages }\end{array}$ & Yes & $\begin{array}{l}94 \% \text { (vs. } \\
78 \%)\end{array}$ & $\begin{array}{l}76 \% \text { (vs. } \\
80 \%)\end{array}$ & $\begin{array}{l}91 \% \text { (vs. } \\
78 \%)\end{array}$ & $\begin{array}{l}\text { WBMRI showed superior accuracy in bone marrow } \\
\text { screening compared to PET-CT. }\end{array}$ \\
\hline [86] & Antoch & 2003 & $\begin{array}{l}98 \text { patients with different } \\
\text { stages }\end{array}$ & No & $\begin{array}{l}90 \% \text { (vs. } \\
93 \%)\end{array}$ & $\begin{array}{l}95 \% \text { (vs. } \\
95 \%)\end{array}$ & $\begin{array}{l}93 \% \text { (vs. } \\
94 \%)\end{array}$ & $\begin{array}{l}\text { PET-CT showed better performance. However, the } \\
\text { WBMRI was performed without DWI. }\end{array}$ \\
\hline [89] & Schmidt & 2008 & $\begin{array}{l}33 \text { patients with breast } \\
\text { cancer and suspicious of } \\
\text { recurrence }\end{array}$ & Yes & $\begin{array}{l}93 \% \text { (vs. } \\
91 \%)\end{array}$ & $\begin{array}{l}86 \% \text { (vs. } \\
90 \%)\end{array}$ & $\begin{array}{l}91 \% \text { (vs. } \\
91 \%)\end{array}$ & $\begin{array}{l}\text { It was also assessed that staging with WBMRI is } \\
\text { feasible at } 1.5 \text { and } 3 \mathrm{~T} \text {, noting that scan time is } \\
\text { reduced at } 3 \mathrm{~T} \text { with identical resolution. }\end{array}$ \\
\hline
\end{tabular}

used with MRI [112]. Novel MRI contrast agents based on iron oxide and dendrimer nanomaterials allow for better characterisation of tumour metastases [112]. Particularly, ultrasmall superparamagnetic particles of iron oxide (USPIOs) imaged with MRI does not require ionising radiation, yet can detect small metastases [113]. The rationale for the use of USPIO is that, after intravenous injection, the nanoparticles are phagocytosed by macrophages in circulation which then enter the interstitial space and are taken up by lymphatics [114-117]. Since iron oxide is superparamagnetic, it becomes strongly magnetic in the strong magnetic field of the MRI leading to spin dephasing and susceptibility effects which result in signal loss. Therefore, the signal intensity is markedly reduced in healthy tissues due to the magnetic susceptibility and T2WI shortening effects of the USPIO particles $[114,118]$. Conversely, in areas of metastases, there is much less uptake of USPIO particles and, therefore, those portions of the LNs remain unchanged in signal on T2WI 24-48 h after intravenous injection of a USPIO [114-117]. Current limits of USPIOs' use include the difficulty of image acquisition/interpretation and the lack of approved USPIOs themselves which are clinically available hinders adoption and larger studies.

Organ-specific MRI contrast agents are also used to identify metastatic disease in the liver. Superparamagnetic iron oxide particles (SPIO) have been approved for clinical practice use as a 'negative contrast agent' for the normal liver parenchyma in order to visualise benign and malignant hepatic cancers [119]. Dendrimer-based macromolecular MRI contrast agents as diaminobutane (DAB) dendrimers, that differ from polyamidoamine (PAMAM) dendrimers because they have a pure aliphatic polyamine interior, homogeneously enhance the liver parenchyma and are excreted more rapidly through both the liver and kidney than the analogous PAMAM dendrimer of similar molecular size [120]. Kobayashi et al. were able to detect small metastatic lesions on the liver from colon cancer cells using DAB dendrimers [120]. Additionally, gadolinium ethoxybenzyl diethylenetriaminepentaacetic acid (Gd-EOB-DTPA) has been developed as a liver-specific contrast agent by a small

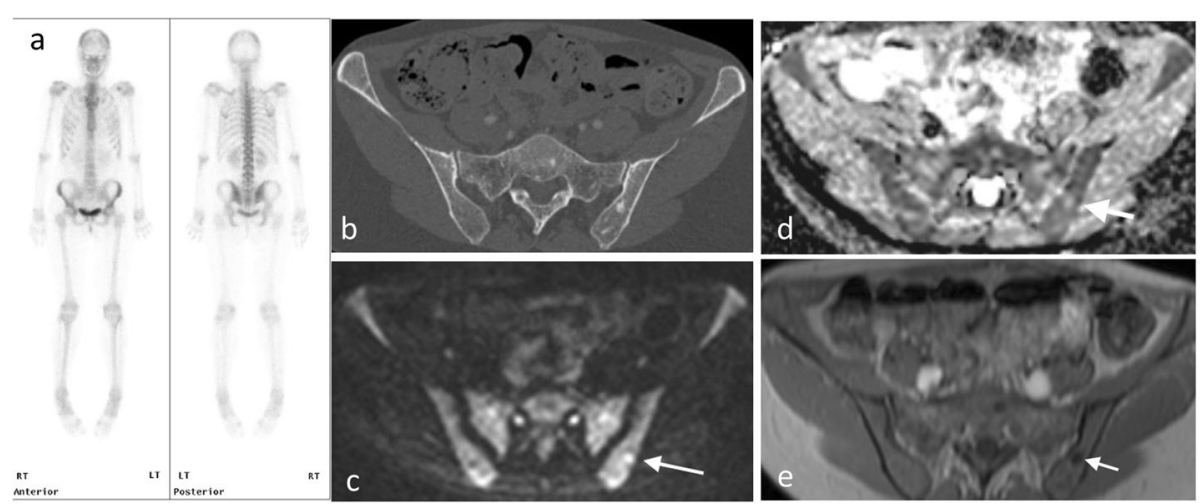

Fig. 7 Evaluation of activity of bone disease on bone scan versus WB-MRI with diffusion. Bone scan (a), CT (b) and WBMRI with diffusion (c and d) and T1-W (e) in a 55-year-old woman with breast cancer post-treatment. The bone scan shows no significant abnormality (a), the CT shows foci of bone sclerosis in the pelvis with a visible lesion in the left posterior ilium (b). The lesions demonstrate low signal on the T1-W image (e) and high signal on DWI and intermediate ADC in keeping with disease 


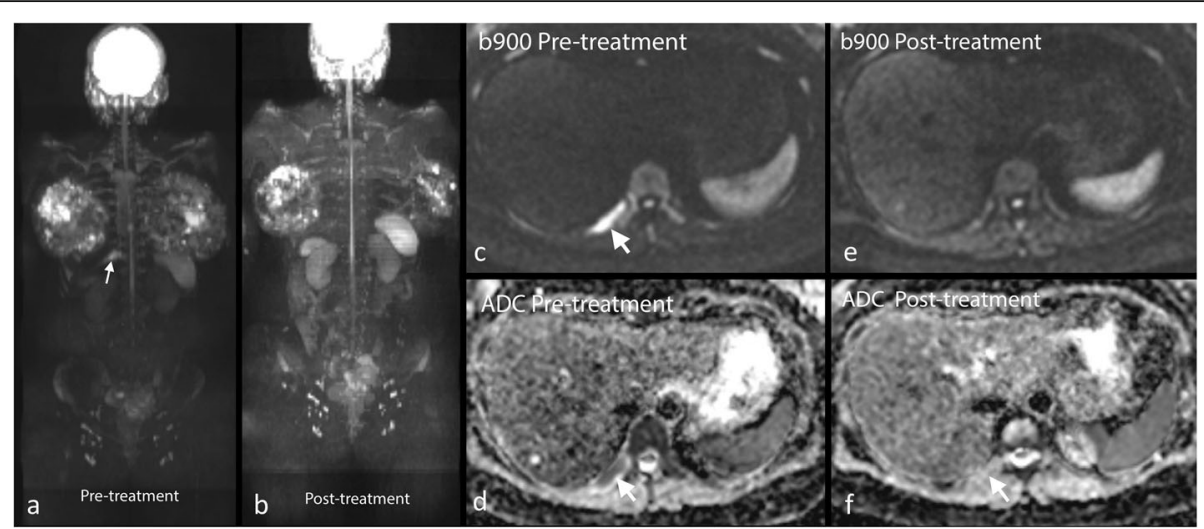

Fig. 8 WBDWI in bone disease following chemotherapy. WB-MRI in a 59-year-old woman with breast cancer. 900 MIP before (a) and after (b) chemotherapy as well as b-900 and ADC maps pre (c and $\mathbf{d}$ ) and post (e and $\mathbf{f}$ ) chemotherapy demonstrate a right 12th rib lesion on with high DWI signal and low ADC on the pretreatment study (white arrow $\mathbf{d}$ ) and complete response of the lesion after treatment (e and $\mathbf{f}$ )

modification of conventional gadolinium-based chelates. As Gd-EOB-DTPA is taken up by hepatocytes, the normal liver parenchyma can be visualised by increased signal intensity at $T 1 \mathrm{WI}$, generating a positive contrast enhancement, where normal liver parenchyma is bright on T1WI and the liver metastases are shown as focal areas of relative hypointensity [121].

Finally, hybrid imaging techniques of combining WBMRI with ${ }^{18} \mathrm{~F}$-choline PET have recently showed to have a significantly higher sensitivity (93.5\%) when compared to BS (63.6\%) and WBMRI on its own (72.7\%) [122]. The results are promising, but with limited access to PET-MRI and its high cost, a defined role of PET and newer advanced hybrid imaging techniques are needed [113]. Stratifying patients according to disease course and treatment status may prove beneficial in the future. Nevertheless, a hybrid role of functional imaging provided by biomarkers with the anatomical detail provided by imaging techniques will offer a valuable insight into disease status.

\section{Limitations}

Substantial heterogeneity was evident in the published literature that were reviewed. Firstly, the quality of the reference standard was variable, relying on combinations of biopsy and/or follow-up. Secondly, there was also variability in the prevalence of bone and visceral metastases across studies. Moreover, we observed that most studies did not quantify how detection of metastases, especially when asymptomatic, influenced the management. As information on treatment and survival were not integrated into such studies, it is not possible to infer the likely prognostic implications of the imaging performance in this patient cohort.

\section{Conclusions}

Accurate M-staging is crucial in the selection of the most appropriate treatment for patients with advanced breast cancer. Although CT, BS and conventional MRI are still the most widely used imaging modalities in this disease setting, advanced imaging techniques are increasingly employed for the earlier and more accurate detection of metastatic disease, for both bones and visceral disease.

\section{Abbreviations \\ BM: Bone metastases; BS: Bone scintigraphy; CT: Computed tomography; DWI: Diffusion-weighted imaging; ER/PR: Oestrogen/progesterone receptor; MRI: Magnetic resonance imaging; NCCN: North-American National Comprehensive Cancer Network; PET: Positron-emission tomography; PPV: Positive predictive value; SPECT: Single-photon emission computerised tomography; WBMRI: Whole-body magnetic resonance imaging; Wl: Weighted imaging}

\section{Acknowledgements}

Artificial Intelligence for Oncology (AIFO) working group which helped the design and the writing of the manuscript

\section{Guarantor}

The scientific guarantor of this publication is Prof. Dow Mu-Koh.

\section{Statistics and biometry}

No complex statistical methods were necessary for this paper.

\section{Authors' contributions}

(1) Conception and design: Filippo Pesapane, Dow-Mu Koh. (2) Administrative support: Dow-Mu Koh. (3) Provision of study materials or patients: all authors. (4) Collection and assembly of data: all authors. (5) Data analysis and interpretation: all authors. (6) Manuscript writing: all authors. (7) Final approval of manuscript: all authors. All authors approved the submitted version and agreed both to be personally accountable for the authors' own contributions and to ensure that questions related to the accuracy or integrity of any part of the work are appropriately investigated, resolved and the resolution documented in the literature.

\section{Authors' information}

Filippo Pesapane is a founder member of the Artificial Intelligence for Oncology (AIFO) working group and he currently works as a radiologist at the European Institute of Oncology (Milan, Italy) at the Breast Imaging Division headed by Prof. Dr. Enrico Cassano. He was a former colleague of 
Dr. Kate Downey and Prof. Dr. Dow Mu-Koh at Royal Marsden Hospital (Sutton, UK)

\section{Funding}

The authors state that this work has not received any funding. Dow Mu-Koh is supported by the funding to the NIHR Clinical Research Facilities and the NIHR Bio-medical Research Centre at the Royal Marsden Hospital and the Institute of Cancer Research.

\section{Availability of data and materials}

Data originating the tables are available on request sent to the corresponding author.

\section{Ethics approval and consent to participate}

Institutional Review Board approval was not required because the research does not involve human populations or animals.

\section{Consent for publication}

The authors of the manuscript have read and agreed to its content and are accountable for all aspects of the accuracy and integrity of the manuscript in accordance with ICMJE criteria.

That the article is original, has not already been published in a journal, and is not currently under consideration by another journal.

Other consent of publications was not required because the research does not involve human populations or animals.

\section{Competing interests}

The authors of this manuscript declare no relationships with any companies, whose products or services may be related to the subject matter of the article.

\section{Author details}

${ }^{1}$ Breast Imaging Division, IEO - European Institute of Oncology IRCCS, Via Giuseppe Ripamonti, 435, 20141 Milano, MI, Italy. ${ }^{2}$ Department of Breast Radiology, Royal Marsden Hospital, Downs Road, Sutton SM2 5PT, UK. ${ }^{3}$ Cancer Research UK Cancer Imaging Centre, The Institute of Cancer Research, 15 Cotswold Road, Sutton SM2 5NG, UK. ${ }^{4}$ Department of Radiology, Royal Marsden Hospital, Downs Road, Sutton SM2 5PT, UK.

\section{Received: 28 February 2020 Accepted: 22 May 2020}

\section{Published online: 16 June 2020}

\section{References}

1. Tan W, Yang M, Yang H, Zhou F, Shen W (2018) Predicting the response to neoadjuvant therapy for early-stage breast cancer: tumor-, blood-, and imaging-related biomarkers. Cancer Manag Res 10:4333-4347

2. National Comprehensive Cancer Network. Clinical practice guidelines in oncology for breast cancer. In. https://www.nccn.org/professionals/ physician_gls/f_guidelines.asp, 2012

3. Howard BE, Phillips J, Miller K et al (2016) SWIFT-Review: a text-mining workbench for systematic review. Syst Rev 5:87

4. Edge SB, Compton CC (2010) The American Joint Committee on Cancer: the 7th edition of the AJCC cancer staging manual and the future of TNM. Ann Surg Oncol 17:1471-1474

5. Amin MB, Greene FL, Edge SB et al (2017) The Eighth Edition AJCC Cancer Staging Manual: continuing to build a bridge from a population-based to a more "personalized" approach to cancer staging. CA Cancer J Clin 67:93-99

6. American Cancer Society. Breast cancer survival rates by stage. In, 2019

7. Lee SJ, Park S, Ahn HK et al (2011) Implications of bone-only metastases in breast cancer: favorable preference with excellent outcomes of hormone receptor positive breast cancer. Cancer Res Treat 43:89-95

8. Pinker K, Chin J, Melsaether AN, Morris EA, Moy L (2018) Precision medicine and radiogenomics in breast cancer: new approaches toward diagnosis and treatment. Radiology 287:732-747

9. Jacobs MA, Macura K, Zaheer A et al (2018) Multiparametric whole-body MRI with diffusion-weighted imaging and ADC mapping for the identification of visceral and osseous metastases from solid tumors. Acad Radiol 25:1405-1414

10. Godinho MV, Lopes F, Costa FM (2018) Whole-body magnetic resonance imaging for the assessment of metastatic breast cancer. Cancer Manag Res 10:6743-6756
11. Tsao MN (2015) Brain metastases: advances over the decades. Ann Palliat Med 4:225-232

12. Penco S, Rotili A, Pesapane F et al (2020) MRI-guided vacuum-assisted breast biopsy: experience of a single tertiary referral cancer centre and prospects for the future. Med Oncol 37:36

13. Pesapane F, Suter MB, Rotili A et al (2020) Will traditional biopsy be substituted by radiomics and liquid biopsy for breast cancer diagnosis and characterisation? Med Oncol 37:29

14. Houssami N, Ciatto S, Macaskill P et al (2008) Accuracy and surgical impact of magnetic resonance imaging in breast cancer staging: systematic review and meta-analysis in detection of multifocal and multicentric cancer. J Clin Oncol 26:3248-3258

15. Cardoso F, Senkus E, Costa A et al (2018) 4th ESO-ESMO international consensus guidelines for advanced breast cancer (ABC 4)dagger. Ann Oncol 29:1634-1657

16. Cardoso F, Kyriakides S, Ohno S et al (2019) Early breast cancer: ESMO clinical practice guidelines for diagnosis, treatment and follow-up. Ann Oncol 30:1674

17. Costelloe CM, Rohren EM, Madewell JE et al (2009) Imaging bone metastases in breast cancer: techniques and recommendations for diagnosis. Lancet Oncol 10:606-614

18. Aebi S, Davidson T, Gruber G, Cardoso F, ESMO Guidelines Working Group (2011) Primary breast cancer: ESMO clinical practice guidelines for diagnosis, treatment and follow-up. Ann Oncol 22 Suppl 6:vi12-vi24

19. The Royal College of Radiologists. Recommendations for cross-sectional imaging in cancer management, breast cancer. In: Clinical Radiology, 2014 $\mathrm{BFCR}(14) 12$

20. Colzani E, Johansson AL, Liljegren A et al (2014) Time-dependent risk of developing distant metastasis in breast cancer patients according to treatment, age and tumour characteristics. Br J Cancer 110:1378-1384

21. Chikarmane SA, Tirumani SH, Howard SA, Jagannathan JP, DiPiro PJ (2015) Metastatic patterns of breast cancer subtypes: what radiologists should know in the era of personalized cancer medicine. Clin Radiol 70:1-10

22. Lee SC, Jain PA, Jethwa SC, Tripathy D, Yamashita MW (2014) Radiologist's role in breast cancer staging: providing key information for clinicians. Radiographics 34:330-342

23. NCCN.org. Breast cancer screening and diagnosis version 3.2018. In: NCCN Clinical Practice Guidelines in Oncology (NCCN Guidelines), 2018

24. Gradishar WJ, Anderson BO, Balassanian R et al (2018) Breast cancer, version 4.2017, NCCN clinical practice guidelines in oncology. J Natl Compr Canc Netw 16:310-320

25. Lecouvet FE, Talbot JN, Messiou C et al (2014) Monitoring the response of bone metastases to treatment with magnetic resonance imaging and nuclear medicine techniques: a review and position statement by the European Organisation for Research and Treatment of Cancer imaging group. Eur J Cancer 50:2519-2531

26. Bjurlin MA, Turkbey B, Rosenkrantz AB, Gaur S, Choyke PL, Taneja SS (2018) Imaging the high-risk prostate cancer patient: current and future approaches to staging. Urology 116:3-12

27. Daldrup-Link HE, Franzius C, Link TM et al (2001) Whole-body MR imaging for detection of bone metastases in children and young adults: comparison with skeletal scintigraphy and FDG PET. AJR Am J Roentgenol 177:229-236

28. Lecouvet FE, El Mouedden J, Collette L et al (2012) Can whole-body magnetic resonance imaging with diffusion-weighted imaging replace Tc $99 \mathrm{~m}$ bone scanning and computed tomography for single-step detection of metastases in patients with high-risk prostate cancer? Eur Urol 62:68-75

29. Shen G, Deng H, Hu S, Jia Z (2014) Comparison of choline-PET/CT, MRI, SPECT, and bone scintigraphy in the diagnosis of bone metastases in patients with prostate cancer: a meta-analysis. Skeletal Radiol 43:1503-1513

30. Love C, Din AS, Tomas MB, Kalapparambath TP, Palestro CJ (2003) Radionuclide bone imaging: an illustrative review. Radiographics 23:341-358

31. Hamaoka T, Madewell JE, Podoloff DA, Hortobagyi GN, Ueno NT (2004) Bone imaging in metastatic breast cancer. J Clin Oncol 22:2942-2953

32. Eustace S, Tello R, DeCarvalho V et al (1997) A comparison of whole-body turboSTIR MR imaging and planar 99mTc-methylene diphosphonate scintigraphy in the examination of patients with suspected skeletal metastases. AJR Am J Roentgenol 169:1655-1661

33. Rybak LD, Rosenthal DI (2001) Radiological imaging for the diagnosis of bone metastases. O J Nucl Med 45:53-64

34. Giovanella L, Castellani M, Suriano S et al (2011) Multi-field-of-view SPECT is superior to whole-body scanning for assessing metastatic bone disease in patients with prostate cancer. Tumori 97:629-633 
35. Nozaki T, Yasuda K, Akashi T, Fuse H (2008) Usefulness of single photon emission computed tomography imaging in the detection of lumbar vertebral metastases from prostate cancer. Int J Urol 15:516-519

36. Palmedo H, Marx C, Ebert A et al (2014) Whole-body SPECT/CT for bone scintigraphy: diagnostic value and effect on patient management in oncological patients. Eur J Nucl Med Mol Imaging 41:59-67

37. Even-Sapir E, Metser U, Mishani E, Lievshitz G, Lerman H, Leibovitch I (2006) The detection of bone metastases in patients with high-risk prostate cancer: 99mTc-MDP Planar bone scintigraphy, single- and multi-field-of-view SPECT, 18F-fluoride PET, and 18F-fluoride PET/CT. J Nucl Med 47:287-297

38. Khalil MM, Tremoleda JL, Bayomy TB, Gsell W (2011) Molecular SPECT imaging: an overview. Int J Mol Imaging 2011:796025

39. Han LJ, Au-Yong TK, Tong WC, Chu KS, Szeto LT, Wong CP (1998) Comparison of bone single-photon emission tomography and planar imaging in the detection of vertebral metastases in patients with back pain. Eur J Nucl Med 25:635-638

40. Venkitaraman R, Sohaib A, Cook G (2007) MRI or bone scan or both for staging of prostate cancer? J Clin Oncol 25:5837-5838 author reply 5838-5839

41. Schirrmeister $\mathrm{H}$, Glatting $\mathrm{G}$, Hetzel J et al (2001) Prospective evaluation of the clinical value of planar bone scans, SPECT, and (18)F-labeled NaF PET in newly diagnosed lung cancer. J Nucl Med 42:1800-1804

42. Abikhzer G, Gourevich K, Kagna O, Israel O, Frenkel A, Keidar Z (2016) Whole-body bone SPECT in breast cancer patients: the future bone scan protocol? Nucl Med Commun 37:247-253

43. Jacobson AF, Fogelman I (1998) Bone scanning in clinical oncology: does it have a future? Eur J Nucl Med 25:1219-1223

44. Rigaud J, Tiguert R, Le Normand L et al (2002) Prognostic value of bone scan in patients with metastatic prostate cancer treated initially with androgen deprivation therapy. J Urol 168:1423-1426

45. Schirrmeister H, Guhlmann A, Elsner K et al (1999) Sensitivity in detecting osseous lesions depends on anatomic localization: planar bone scintigraphy versus 18F PET. J Nucl Med 40:1623-1629

46. Helyar V, Mohan HK, Barwick T et al (2010) The added value of multislice SPECT/CT in patients with equivocal bony metastasis from carcinoma of the prostate. Eur J Nucl Med Mol Imaging 37:706-713

47. Heindel W, Gubitz R, Vieth V, Weckesser M, Schober O, Schafers M (2014) The diagnostic imaging of bone metastases. Dtsch Arztebl Int 111:741-747

48. Hagemeister FB Jr, Buzdar AU, Luna MA, Blumenschein GR (1980) Causes of death in breast cancer: a clinicopathologic study. Cancer 46:162-167

49. Patella F, Pesapane F, Fumarola EM et al (2018) CT-MRI LI-RADS v2017: a comprehensive guide for beginners. J Clin Transl Hepatol 6:222-236

50. Ghobrial FEl, Eldin MS, Razek A, Atwan NI, Shamaa SSA (2017) Computed tomography assessment of hepatic metastases of breast cancer with revised Response Evaluation Criteria in Solid Tumors (RECIST) criteria (version 1.1): inter-observer agreement. Pol J Radiol 82:593-597

51. Floriani I, Torri V, Rulli E et al (2010) Performance of imaging modalities in diagnosis of liver metastases from colorectal cancer: a systematic review and meta-analysis. J Magn Reson Imaging 31:19-31

52. Kennecke $H$, Yerushalmi R, Woods R et al (2010) Metastatic behavior of breast cancer subtypes. J Clin Oncol 28:3271-3277

53. Slamon DJ, Leyland-Jones B, Shak S et al (2001) Use of chemotherapy plus a monoclonal antibody against HER2 for metastatic breast cancer that overexpresses HER2. N Engl J Med 344:783-792

54. Brookes M, MacVicar D, Husband J (2007) Metastatic carcinoma of the breast: the appearances of metastatic spread to the abdomen and pelvis as demonstrated by CT. Br J Radiol 80:284-292

55. Mhlanga JC, Evans AE, Doyle $S$ et al (2011) The prognostic significance of computerised tomography findings in women with liver metastases from breast cancer. Breast 20:455-459

56. Foulkes WD, Smith IE, Reis-Filho JS (2010) Triple-negative breast cancer. N Engl J Med 363:1938-1948

57. Kaplan MA, Ertugrul H, Firat $U$ et al (2015) Brain metastases in HER2-positive metastatic breast cancer patients who received chemotherapy with or without trastuzumab. Breast Cancer 22:503-509

58. Perez-Lopez R, Mateo J, Mossop H et al (2017) Diffusion-weighted imaging as a treatment response biomarker for evaluating bone metastases in prostate cancer: a pilot study. Radiology 283:168-177

59. Ghanem N, Altehoefer C, Hogerle S et al (2002) Comparative diagnostic value and therapeutic relevance of magnetic resonance imaging and bone marrow scintigraphy in patients with metastatic solid tumors of the axia skeleton. Eur J Radiol 43:256-261
60. Daffner RH, Lupetin AR, Dash N, Deeb ZL, Sefczek RJ, Schapiro RL (1986) MR in the detection of malignant infiltration of bone marrow. AJR Am J Roentgenol 146:353-358

61. Schirrmeister H, Guhlmann A, Kotzerke J et al (1999) Early detection and accurate description of extent of metastatic bone disease in breast cancer with fluoride ion and positron emission tomography. J Clin Oncol 17:23812389

62. Steinborn MM, Heuck AF, Tiling R, Bruegel M, Gauger L, Reiser MF (1999) Whole-body bone marrow MRI in patients with metastatic disease to the skeletal system. J Comput Assist Tomogr 23:123-129

63. Horvath $\sqcup$, Burtness BA, McCarthy S, Johnson KM (1999) Total-body echoplanar MR imaging in the staging of breast cancer: comparison with conventional methods--early experience. Radiology 211:119-128

64. Walker R, Kessar P, Blanchard R et al (2000) Turbo STIR magnetic resonance imaging as a whole-body screening tool for metastases in patients with breast carcinoma: preliminary clinical experience. J Magn Reson Imaging 11: 343-350

65. Altehoefer C, Ghanem N, Hogerle S, Moser E, Langer M (2001) Comparative detectability of bone metastases and impact on therapy of magnetic resonance imaging and bone scintigraphy in patients with breast cancer. Eur J Radiol 40:16-23

66. Kim DS, Hong SH, Choi JY et al (2009) Magnetic resonance imaging diagnoses of bone scan abnormalities in breast cancer patients. Nucl Med Commun 30:736-741

67. Houssami N, Costelloe CM (2012) Imaging bone metastases in breast cancer: evidence on comparative test accuracy. Ann Oncol 23:834-843

68. Schmidt GP, Reiser MF, Baur-Melnyk A (2009) Whole-body MRI for the staging and follow-up of patients with metastasis. Eur J Radiol 70:393-400

69. Michaels AY, Keraliya AR, Tirumani SH, Shinagare AB, Ramaiya NH (2016) Systemic treatment in breast cancer: a primer for radiologists. Insights Imaging 7:131-144

70. Namasivayam S, Martin DR, Saini S (2007) Imaging of liver metastases: MR Cancer Imaging 7:2-9

71. Braga L, Semelka RC, Pietrobon R, Martin D, de Barros N, Guller U (2004) Does hypervascularity of liver metastases as detected on MRI predict disease progression in breast cancer patients? AJR Am J Roentgenol 182:1207-1213

72. Pope WB (2018) Brain metastases: neuroimaging. Handb Clin Neurol 149:89-112

73. Fink KR, Fink JR (2013) Imaging of brain metastases. Surg Neurol Int 4:S209-S219

74. Kruger S, Mottaghy FM, Buck AK et al (2011) Brain metastasis in lung cancer Comparison of cerebral MRI and 18F-FDG-PET/CT for diagnosis in the initial staging. Nuklearmedizin 50:101-106

75. Ramakrishna N, Temin S, Lin NU (2018) Recommendations on disease management for patients with advanced human epidermal growth factor receptor 2-positive breast cancer and brain metastases: ASCO clinical practice guideline update summary. J Oncol Pract 14:505-507

76. Thoeny HC, Barbieri S, Froehlich JM, Turkbey B, Choyke PL (2017) Functional and targeted lymph node imaging in prostate cancer: current status and future challenges. Radiology 285:728-743

77. Petren-Mallmin M, Andreasson I, Ljunggren O et al (1998) Skeletal metastases from breast cancer: uptake of 18F-fluoride measured with positron emission tomography in correlation with CT. Skeletal Radiol 27:72-76

78. Even-Sapir E, Metser U, Flusser $\mathrm{G}$ et al (2004) Assessment of malignant skeletal disease: initial experience with 18F-fluoride PET/CT and comparison between 18F-fluoride PET and 18F-fluoride PET/CT. J Nucl Med 45:272-278

79. Cook GJ, Azad GK, Goh V (2016) Imaging bone metastases in breast cancer: staging and response assessment. J Nucl Med 57(Suppl 1):27S-33S

80. Dashevsky BZ, Goldman DA, Parsons M et al (2015) Appearance of untreated bone metastases from breast cancer on FDG PET/CT: importance of histologic subtype. Eur J Nucl Med Mol Imaging 42:1666-1673

81. Israel O, Goldberg A, Nachtigal A et al (2006) FDG-PET and CT patterns of bone metastases and their relationship to previously administered anticancer therapy. Eur J Nucl Med Mol Imaging 33:1280-1284

82. Catalano OA, Daye D, Signore A et al (2017) Staging performance of wholebody DWI, PET/CT and PET/MRI in invasive ductal carcinoma of the breast. Int J Oncol 51:281-288

83. Koolen BB, Vrancken Peeters MJ, Aukema TS et al (2012) 18F-FDG PET/CT as a staging procedure in primary stage II and III breast cancer: comparison with conventional imaging techniques. Breast Cancer Res Treat 131:117-126

84. Brennan ME, Houssami N (2012) Evaluation of the evidence on staging imaging for detection of asymptomatic distant metastases in newly diagnosed breast cancer. Breast 21:112-123 
85. Minamimoto $R$, Loening A, Jamali M et al (2015) Prospective comparison of 99mTc-MDP scintigraphy, combined 18F-NaF and 18F-FDG PET/CT, and whole-body MRI in patients with breast and prostate cancer. J Nucl Med 56: 1862-1868

86. Antoch G, Vogt FM, Freudenberg LS et al (2003) Whole-body dual-modality PET/CT and whole-body MRI for tumor staging in oncology. JAMA 290: 3199-3206

87. Melsaether AN, Raad RA, Pujara AC et al (2016) Comparison of whole-body (18)F FDG PET/MR imaging and whole-body (18)F FDG PET/CT in terms of lesion detection and radiation dose in patients with breast cancer. Radiology 281:193-202

88. Birim O, Kappetein AP, Stijnen T, Bogers AJ (2005) Meta-analysis of positron emission tomographic and computed tomographic imaging in detecting mediastinal lymph node metastases in nonsmall cell lung cancer. Ann Thorac Surg 79:375-382

89. Schmidt GP, Baur-Melnyk A, Haug A et al (2008) Comprehensive imaging of tumor recurrence in breast cancer patients using whole-body MRI at 1.5 and 3 T compared to FDG-PET-CT. Eur J Radiol 65:47-58

90. Bluemel C, Krebs M, Polat B et al (2016) 68Ga-PSMA-PET/CT in patients with biochemical prostate cancer recurrence and negative 18F-choline-PET/CT. Clin Nucl Med 41:515-521

91. Ehman EC, Johnson GB, Villanueva-Meyer JE et al (2017) PET/MRI: where might it replace PET/CT? J Magn Reson Imaging 46:1247-1262

92. Schaarschmidt BM, Grueneisen J, Heusch P et al (2015) Oncological wholebody staging in integrated (18)F-FDG PET/MR: value of different MR sequences for simultaneous PET and MR reading. Eur J Radiol 84:1285-1292

93. Huellner MW, de Galiza BF, Husmann L et al (2016) TNM staging of nonsmall cell lung cancer: comparison of PET/MR and PET/CT. J Nucl Med 57: 21-26

94. Grueneisen J, Sawicki LM, Schaarschmidt BM et al (2016) Evaluation of a fast protocol for staging lymphoma patients with integrated PET/MRI. PLoS One 11:e0157880

95. Grueneisen J, Schaarschmidt BM, Heubner M et al (2015) Implementation of FAST-PET/MRI for whole-body staging of female patients with recurrent pelvic malignancies: a comparison to PET/CT. Eur J Radiol 84:2097-2102

96. Catalano OA, Nicolai E, Rosen BR et al (2015) Comparison of CE-FDG-PET/CT with CE-FDG-PET/MR in the evaluation of osseous metastases in breast cancer patients. Br J Cancer 112:1452-1460

97. Raad RA, Friedman KP, Heacock L, Ponzo F, Melsaether A, Chandarana H (2016) Outcome of small lung nodules missed on hybrid PET/MRI in patients with primary malignancy. J Magn Reson Imaging 43:504-511

98. Riola-Parada C, Garcia-Canamaque L, Perez-Duenas V, Garcerant-Tafur M, Carreras-Delgado JL (2016) Simultaneous PET/MRI vs PET/CT in oncology. a systematic review. Rev Esp Med Nucl Imagen Mol 35:306-312

99. Matsubayashi RN, Fujii T, Yasumori K, Muranaka T, Momosaki S (2010) Apparent diffusion coefficient in invasive ductal breast carcinoma: correlation with detailed histologic features and the enhancement ratio on dynamic contrast-enhanced MR Images. J Oncol 2010:821048

100. Padhani AR, Liu G, Koh DM et al (2009) Diffusion-weighted magnetic resonance imaging as a cancer biomarker: consensus and recommendations. Neoplasia 11:102-125

101. Rotili A, Trimboli RM, Penco S et al (2020) Double reading of diffusionweighted magnetic resonance imaging for breast cancer detection. Breast Cancer Res Treat 180(1):111-120

102. Koh DM, Blackledge M, Padhani AR et al (2012) Whole-body diffusionweighted MRI: tips, tricks, and pitfalls. AJR Am J Roentgenol 199:252-262

103. Lauenstein TC, Freudenberg LS, Goehde SC et al (2002) Whole-body MRI using a rolling table platform for the detection of bone metastases. Eur Radiol 12:2091-2099

104. Ma J, Costelloe CM, Madewell JE et al (2009) Fast dixon-based multisequence and multiplanar MRI for whole-body detection of cancer metastases. J Magn Reson Imaging 29:1154-1162

105. Heusner TA, Kuemmel S, Koeninger A et al (2010) Diagnostic value of diffusion-weighted magnetic resonance imaging (DWI) compared to FDG PET/CT for whole-body breast cancer staging. Eur J Nucl Med Mol Imaging 37:1077-1086

106. Gutzeit A, Doert A, Froehlich JM et al (2010) Comparison of diffusionweighted whole body MRI and skeletal scintigraphy for the detection of bone metastases in patients with prostate or breast carcinoma. Skeletal Radiol 39:333-343
107. Schmidt GP, Schoenberg SO, Schmid R et al (2007) Screening for bone metastases: whole-body MRI using a 32-channel system versus dualmodality PET-CT. Eur Radiol 17:939-949

108. Padhani AR, van Ree K, Collins DJ, D'Sa S, Makris A (2013) Assessing the relation between bone marrow signal intensity and apparent diffusion coefficient in diffusion-weighted MRI. AJR Am J Roentgenol 200:163-170

109. Dietrich O, Geith T, Reiser MF, Baur-Melnyk A (2017) Diffusion imaging of the vertebral bone marrow. NMR Biomed 30

110. Engelhard K, Hollenbach HP, Wohlfart K, von Imhoff E, Fellner FA (2004) Comparison of whole-body MRI with automatic moving table technique and bone scintigraphy for screening for bone metastases in patients with breast cancer. Eur Radiol 14:99-105

111. Harmon SAS, Bergvall E, Mena E et al (2018). A prospective comparison of (18)F-sodium fluoride PET/CT and PSMA-targeted (18)F-DCFBC PET/CT in metastatic prostate cancer. J Nucl Med 59:1665-1671

112. McCann TE, Kosaka N, Turkbey B, Mitsunaga M, Choyke PL, Kobayashi H (2011) Molecular imaging of tumor invasion and metastases: the role of MRI. NMR Biomed 24:561-568

113. Czarniecki M, Pesapane F, Wood BJ, Choyke P, Turkbey B (2018) Ultra-small superparamagnetic iron oxide contrast agents for lymph node staging of high-risk prostate cancer. Transl Androl Urol 7(Suppl 4):S453-S461

114. Harisinghani MG, Dixon WT, Saksena MA et al (2004) MR lymphangiography: imaging strategies to optimize the imaging of lymph nodes with ferumoxtran-10. Radiographics 24:867-878

115. Birkhauser FD, Studer UE, Froehlich JM et al (2013) Combined ultrasmall superparamagnetic particles of iron oxide-enhanced and diffusion-weighted magnetic resonance imaging facilitates detection of metastases in normalsized pelvic lymph nodes of patients with bladder and prostate cancer. Eur Urol 64:953-960

116. Fortuin AS, Bruggemann R, van der Linden J et al (2018) Ultra-small superparamagnetic iron oxides for metastatic lymph node detection: back on the block. Wiley Interdiscip Rev Nanomed Nanobiotechnol 10:1471

117. Corot C, Robert P, Idee JM, Port M (2006) Recent advances in iron oxide nanocrystal technology for medical imaging. Adv Drug Deliv Rev 58:14711504

118. Harisinghani MG, Barentsz J, Hahn PF et al (2003) Noninvasive detection of clinically occult lymph-node metastases in prostate cancer. N Engl J Med 348:2491-2499

119. Reimer $P$, Jahnke $N$, Fiebich $M$ et al (2000) Hepatic lesion detection and characterization: value of nonenhanced MR imaging, superparamagnetic iron oxide-enhanced MR imaging, and spiral CT-ROC analysis. Radiology 217:152-158

120. Kobayashi H, Kawamoto S, Saga T et al (2001) Novel liver macromolecular MR contrast agent with a polypropylenimine diaminobutyl dendrimer core: comparison to the vascular MR contrast agent with the polyamidoamine dendrimer core. Magn Reson Med 46:795-802

121. Vogl TJ, Kummel S, Hammerstingl R et al (1996) Liver tumors: comparison of MR imaging with Gd-EOB-DTPA and Gd-DTPA. Radiology 200:59-67

122. Metser U, Berlin A, Halankar J et al (2018) (18)F-Fluorocholine PET wholebody MRI in the staging of high-risk prostate cancer. AJR Am J Roentgenol 210:635-640

\section{Publisher's Note}

Springer Nature remains neutral with regard to jurisdictional claims in published maps and institutional affiliations. 